\title{
Prevalence of Pathologies Associated with Impacted Third Molars in Kosovo Population: an Orthopantomographic Study
}

\section{Učestalost patoloških promjena povezanih s impaktiranim trećim kutnjacima među kosovskim stanovništvom: ortopantomografska studija}

\author{
${ }^{1}$ Department of Oral Surgery, University Dentistry Clinical Center of Kosovo, Pristina, Kosovo \\ Zavod za oralnu kirurgiju, Sveučilišni stomatološki klinički centar Kosova, Priština, Kosovo \\ 2 Human Dental Anatomy and Morphology, University of Pristina, Medical Faculty, School of Dentistry, Pristina, Kosovo \\ Zavod za dentalnu anatomiju i morfologiju, Sveučilište u Prištini, Medicinski fakultet, Studij stomatologije, Priština, Kosovo \\ ${ }^{3}$ Department of Dental Pathology and Endodontics, University of Pristina, Medical Faculty, School of Dentistry, Pristina, Kosovo \\ Zavod za dentalnu patologiju i endodonciju, Medicinski fakultet, Studij stomatologije, Priština, Kosovo \\ ${ }^{4}$ School of Dental Medicine, University Zagreb, Department of Oral and Maxillofacial Surgery, University Hospital Dubrava, Zagreb, Croatia \\ Stomatološki fakultet Sveučilišta u Zagrebu, Klinička bolnica Dubrava, Klinika za kirurgiju lica, čeljusti i usta, Zagreb, Hrvatska
}

\section{Abstract}

Objective: The aim of this study was to evaluate the prevalence of pathologies associated with impacted third molars radiographically noticeable in a Kosovar population, as currently no data are available. Methods and Materials: This was a retrospective study of 5515 panoramic images of patients who visited the University Dentistry Clinical Center of Kosovo. Of these 5515 patients, 2368 were males and 3147 were females. The age range was from 18 to 77 years. We reviewed panoramic images in order to determine the number of pathologies associated with impacted third molars. The following radiographic lesions were recorded: caries of impacted teeth and/or adjacent tooth, root resorption of adjacent tooth, periodontal bone loss of adjacent tooth of more than $5 \mathrm{~mm}$ below the cemento-enamel junction and an increase in pericoronar gap over $4 \mathrm{~mm}$. Results: The prevalence of pathologies associated with impacted third molar in Kosovar population was $29.5 \%$. Root resorption of adjacent tooth had the highest frequency of pathology 307 (23.7\%). It was followed by periodontal bone loss of adjacent tooth of more than $5 \mathrm{~mm} 71$ (5.5\%) and caries $33(2.5 \%)$. The lowest was an increase in pericoronar gap 15 (1.2\%). Conclusion: The most common pathology was root resorption, with the highest incidence of pathology localized in the maxilla $159(32.3 \%)$. The prevalence of periodontal bone loss, caries and increase in pericoronar gap was significantly lower. The findings of our research could have an impact on development of prevention strategies that will proficiently deal with pathologies that result from impacted teeth.
Received: December 9, 2018

Accepted: March 12, 2019

Address for correspondence Zana Sejfija

PhD Student-University of Zagreb University of Pristina

Medical Faculty

School of Dentistry

Rr. Bulevardi i Dëshmorëve, p.n.

10000 Pristina, Kosovo

Phone: +37744169076

zana.sejija@uni-pr.edu

Key words

Tooth, Impacted; Panoramic Radiography; Root Resorption; Dental Caries; Alveolar Bone Loss; Prevalence; Third molar

\section{Introduction}

Third molars have the highest incidence of impaction in human dentition and their values have been on a rise (1-4).

As a result, the most frequent procedure in oral surgery worldwide is a removal of impacted third molars $(5,6)$. An impacted tooth, that is, the impacted third molar is a pathological condition in which tooth fails or is not excepted to erupt into the dental arch based on clinical and radiographic findings (7). Failure of these teeth to erupt might be a consequence of late maturation of these teeth, an increased crown size, distal eruption of dentition lack of space, malposition or limited skeletal growth $(2,8-10)$.

An impacted maxillary and mandibular molar may take a variety of positions and levels of impaction, which can result with a range of pathologies associated with their impac-
Uvod

U ljudskoj denticiji najčešća je impakcija trećih kutnjaka i njihov broj je u porastu $(1-4)$. Kao posljedica toga, najčešći oralno-kirurški zahvat diljem svijeta jest uklanjanje trećih kutnjaka $(5,6)$. Impaktirani zub, odnosno treći kutnjak, patološko je stanje u kojemu zub ne uspijeva, ili se na temelju kliničkih i radiografskih nalaza ne očekuje da nikne u zubni luk (7). Neuspjeh nicanja tih zuba može biti posljedica njihova kasnog sazrijevanja, povećane veličine krune, distalnog nedostatka prostora, malformacije ili ograničenog rasta skeleta $(2,8-10)$.

Impaktirani maksilarni i mandibularni kutnjak može imati različite položaje i razinu impakcije, što može rezultirati nizom povezanih patoloških promjena $(2,5)$. Najčešće patološke promjene povezane $s$ trećim kutnjacima su karijes 
tion $(2,5)$. Most common pathologies associated with third molars are caries of impacted teeth or adjacent tooth, second molar tooth resorption, periodontal bone loss of adjacent tooth and odontogenic cysts $(5,11)$.

A great deal of discussion has been taking place worldwide about the suggestion for retaining or extraction of impacted third molar and it remains ongoing $(2,11-12)$. An extremely wide-ranged and balanced review of this topic has been published by Mercier and Precious (14). In their article they emphasized that from 149 publications they have referred to, they concluded that for particular patient significant risks and benefits must be considered individually. Furthermore, oral surgeons are those who should act in the patient's best interests during the evaluation of the third molar extraction (14).

In 1979, the National Institute for Dental Research, supported a conference dedicated to third molar, with main intention to reach an agreement about when should third molar extraction be advised and under what circumstances (15). Since then guidelines for management of impacted third molars have been published $(16,17)$, the National Institute of Clinical Excellence (16) and the Scottish Intercollegiate Guidelines Network (17) have established the guidelines for removal of third molar, which were reviewed in 2005, and today they are foundations for ethical clinical practice. Considering the danger and cost (see Table 3) associated with third molar extractions, they concluded that there was no proper indication to support prophylactic removal of asymptomatic impacted third molars. On the other hand, the above mentioned guidelines did not consider recommendations by the American Association of Oral and Maxillofacial surgeons, supporting extraction of asymptomatic third molars considering that they are a potential cause of chronic inflammation, affecting patients to a range of periodontal and systemic problems in the future. The conclusions from the above mentioned studies were that extraction of third molars should only be carried out in the presence of pathology (18-21).

Therefore, it is of utmost importance to be familiar with the prevalence of pathologies associated with impacted third molars (1).

Despite the fact that until today there have been several studies concerning the potential development of pathologies associated with impacted third molars in populations from different countries $(1,22-34)$, the evidence is frequently inconsistent. Nitzan et al (27) report a prevalence of $8 \%$ of root resorption of second molar adjacent to impacted third molar. A long term study by Kahl B et al. (35), where they evaluated tooth resorption on asymptomatic third molars in orthodontically treated patients, resulted with a prevalence of $8 \%$ resorption of upper second molar and $9.5 \%$ of lower second molar. However, Sewerin and von Wowern (36), reported about the zero root resorption of adjacent second molar by impacted third molar.

Considering the fact that at present the frequency of pathologies associated with impacted third molars in Kosovar populations has not yet been evaluated, the aim of this study was to determine the prevalence of caries, periodontal bone loss of adjacent tooth and increase over $4 \mathrm{~mm}$ in pericoronar space in Kosovar population visible on panoramic images. impaktiranih zuba ili susjednoga zuba, resorpcija drugog kutnjaka, gubitak parodontne kosti susjednoga zuba i odontogene ciste $(5,11)$.

Mnogo je rasprava o zadržavanju ili vađenju trećega kutnjaka, a ta se tema i dalje često analizira. (2, 11 - 13). Iznimno širok i uravnotežen pregled o tome objavili su Mercier i Precious (14). U svojem su članku, na temelju analize 149 studija, zaključili da se za određenog pacijenta pojedinačni rizici i koristi moraju razmatrati individualno. Nadalje, tijekom procjene ekstrakcije trećeg kutnjaka oralni kirurzi trebaju primarno biti usmjereni na interes pacijenta (14).

Godine 1979. podržao je National Institute for Dental Research konferenciju posvećenu trećem kutnjacima, a glavna namjera je bila postići dogovor o tome kada se treba savjetovati ekstrakcija trećeg kutnjaka i u kojim okolnostima (15). Od tada su objavljene smjernice za postupak s impaktiranim trećim kutnjacima $(16,17)$. National Institute of Clinical Excellence (16) i Scottish Intercollegiate Guidelines Network (17) odredili su smjernice za uklanjanje trećeg kutnjaka i one su danas temelj za etičku kliničku praksu. Nadopunjene su 2005. godine. Zaključili su da, s obzirom na potencijalnu opasnost od zahvata i troškove (tablica 3.) povezane $s$ ekstrakcijom trećega kutnjaka, nema odgovarajuće indikacije za profilaktično uklanjanje asimptomatskih trećih kutnjaka. $S$ druge strane, iste smjernice nisu uzimale u obzir preporuke Američke udruge oralnih i maksilofacijalnih kirurga, podupirajući ekstrakciju asimptomatskih trećih kutnjaka s obzirom na to da su oni potencijalni uzrok kronične upale koja može nastati u obliku parodontnih i sistemskih problema. Zaključci gore navedenih studija su da treće kutnjake treba izvaditi jedino ako postoje određene patološke promjene $(18-21)$. Zato je važno poznavati učestalost patoloških promjena povezanih s impaktiranim trećim kutnjacima (1).

Unatoč činjenici da do danas postoji nekoliko studija o potencijalnom razvoju patoloških promjena povezanih $s$ impaktiranim trećim kutnjacima u populaciji različitih zemalja $(1,22-34)$, rezultati često nisu dosljedni. Nitzan i suradnici (27) navode prevalenciju od $8 \%$ resorpcije korijena drugog kutnjaka. Dugoročna studija Kahla i suradnika (35) u kojoj su procjenjivali resorpciju asimptomatskih trećih kutnjaka kod ortodontski liječenih bolesnika, rezultirala je učestalošću resorpcije drugoga gornjeg kutnjaka od $8 \%$ i 9,5 \% drugoga donjeg kutnjaka. No Sewerin i von Wowern (36) nisu uočili resorpciju korijena susjednoga drugog kutnjaka uzrokovanu impaktiranim trećim kutnjakom.

Budući da na ortopantomogramima još nije istražena učestalost patoloških promjena povezanih $s$ impaktiranim trećim kutnjacima među kosovskim stanovništvom, cilj ove studije jest utvrditi učestalost karijesa, gubitka parodontne kosti susjednoga zuba i povećanje perikoronarnog prostora veće od $4 \mathrm{~mm}$ među kosovskim stanovništvom. 


\section{Methods and Material}

In this retrospective study, OPGs were obtained at the University Dentistry Clinical Center of Kosovo and analyzed for the pathologies associated with an impacted third molar. OPGs were taken as a standard procedure for all visiting patients. Consent forms of approval were signed by patients wherein they stated that their radiographs could only be used for educational and research purposes. The study protocol was approved by UDCCK and University of Zagreb School of Dental Medicine.

In this study, the inclusion criteria were as follows: OPGs of patients with minimum age of 18 years or older, males and females with all forms of impaction. OPGs with low quality were excluded from the study, including third molars with incomplete root formation. To collect patients' data, their dates of birth and genders were used.

Panoramic radiographies were retrieved as digitalized images from the UCCK's database. Images from the digital OPG machine were exported to JPEG format using the Sidexis Next generation imaging software, version $2.4^{\oplus}$, integrated with the I-Max Touch Line:220-240V-7A 50/60Hz max exposure time: $15 \mathrm{~s}$, produced by Owandy (OWANDY 6, allée Kepler 77420 Champs-sur-Marne - FRANCE) ${ }^{\oplus}$.

Third molar was defined as impacted with no functional occlusion, since it was not allowed to erupt on its eruption path by other tooth, soft tissue or bone and its roots were fully formed (23). Primarily, impacted third maxillary and mandibular molars were identified in the OPG. Afterwards, the following radiographic lesions were recorded on OPG's: caries in impacted teeth and adjacent tooth, periodontal bone loss on distal side of the second mandibular and maxillary molar, adjacent tooth root resorption and increased pericoronal space of dental follicle.

The norms for diagnosing pathologies associated with impacted third molar in maxilla or mandible were as follows: clear carious lesion noticed in OPG in the impacted third molar or in the adjacent second, The periodontal bone loss of the distal part of the second molar was measured from the cement-enamel junction to the marginal bone level over $5 \mathrm{~mm}$; Root resorption of adjacent tooth to impacted third molar on OPG, was a clear loss of substance in the root of second molar in maxilla and mandible due to direct contact between impacted third molar and adjacent tooth; Increase in the pericoronal space of the dental follicle over $4 \mathrm{~mm}$ around third impacted molar.

For the measurement of the above mentioned dimensions we used ruler from the coral draw.

\section{Statistical analysis}

Data were analyzed using a Pearson chi-square test using the Statistical Package for the Social Sciences (version 18.0; SPSS, Inc, Chicago, IL). The age, gender, number of impacted third molars associated with pathologies was displayed by frequency and percentage. The relationships between the groups were analyzed using the Pearson chi-square test. The results were considered statistically significant if the $\mathrm{p}$-value was less than $5 \%(p<0.05)$.

All OPGs were assessed by a single examiner (ZS), a PhD candidate, to eliminate inter-examiner errors. The validity of

\section{Materijal i postupci}

U ovom retrospektivnom istraživanju OPG-ova u Sveučilišnom stomatološkom centru Kosova analizirali smo patološke promjene povezane s impaktiranim trećim kutnjakom. OPG-ovi su snimljeni kao standardni postupak. Svi pacijenti potpisali su informirani pristanak da se njihove rendgenske snimke mogu upotrijebiti jedino u obrazovne i istraživačke svrhe. Protokol istraživanja odobrili su Etičko povjerenstvo UDCCK-a i Etičko povjerenstvo Stomatološkog fakulteta Sveučilišta u Zagrebu.

Kriteriji za sudjelovanje bili su sljedeći: pacijenti u dobi od 18 godina ili stariji, pacijenti obaju spolova sa svim oblicima impakcije. OPG-ovi niske kvalitete isključeni su iz istraživanja, kao i treći kutnjaci s nepotpuno formiranim korijenima. Zabilježeni su podatci o datumu rođenja i spolu pacijenata.

Panoramske snimke preuzete su kao digitalizirane snimke iz baze podataka UDCCK-a. Digitalizirane snimke prebačene su u JPEG format s pomoću softvera za obradu slika Sidexis, inačica $2,4^{\oplus}$, integrirana s I-Max Touch Lineom: 220-240V-7A $50 / 60 \mathrm{~Hz}$, maksimalno vrijeme ekspozicije 15 s, proizvodi Owandy ( OWANDY 6, allée Kepler 77420 Champs-sur-Marne - Francuska) ${ }^{\oplus}$.

Treći kutnjak definiran je kao impaktiran ako nije u funkcijskoj okluziji, zato što nije mogao niknuti zbog zapreke drugim zubima, mekim tkivima ili kostima, a korijeni su potpuno formirani (25). Najprije je na OPG-u identificiran impaktirani treći kutnjak u gornjoj i donjoj čeljusti. Nakon toga zabilježene su sljedeće radiografske promjene na OPG$\mathrm{u}$ : karijes impaktiranoga i susjednoga zuba, gubitak parodonthe kosti na distalnoj strani drugoga kutnjaka obiju čeljusti, resorpcija korijena susjednoga zuba i povećani perikoronarni prostor zubnoga folikula.

Kriteriji za dijagnosticiranje patoloških promjena povezanih s trećim kutnjakom u gornjoj ili donjoj čeljusti: na OPGu utvrđena jasna karijesna lezija trećega kutnjaka ili susjednoga drugog kutnjaka; gubitak parodontne kosti veći od $5 \mathrm{~mm}$ distalnoga dijela drugoga kutnjaka izmjeren od caklinsko-cementnog spojišta do razine marginalnoga dijela kosti; resorpcija korijena susjednoga zuba uz treći kutnjak bila je jasan gubitak tkiva korijena drugog kutnjaka u obje čeljusti zbog izravnoga kontakta između trećeg kutnjaka i susjednoga zuba; povećanje perikoronarnoga prostora zubnog folikula veće od $4 \mathrm{~mm}$ oko impaktiranoga trećeg kutnjaka.

$\mathrm{Za}$ mjerenje gore navedenih dimenzija koristili smo se ravnalom iz programa Corel draw.

\section{Statistička analiza}

Podatci su analizirani Pearsonovim hi-kvadrat testom izvedenim korištenjem Statistical Package for the Social Sciencesa (verzija 18,0; SPSS, Inc, Chicago, IL, SAD). Dob, spol i broj impaktiranih trećih kutnjaka povezanih s patološkim promjenama prikazan je prema učestalosti i postotku. Odnosi između skupina analizirani su Pearsonovim hikvadrat testom. Rezultati su smatrani statistički značajnima ako je p-vrijednost manja od $5 \%(\mathrm{p}<0,05)$. Sve OPG-ove ocjenjivao je jedan ispitivač kako bi se izbjegle pogreške među ispitivačima. Valjanost očitanja OPG-ova ispitana je za 99 
the OPG readings was tested for 99 impacted third molars observed on 50 randomly selected OPGs using Kappa statistics (36).

Two weeks after the first evaluation by the first author (ZS), the evaluation was repeated by the last author (FK). All OPGs were examined using a blind approach, without the possibility of evaluating age and gender. The average of the coefficients obtained for the relevant variables of this study was substantial (0.756).

\section{Results}

In our retrospective study, we screened the data of 5515 adult patients who were referred at the UCCK, of these 3147 $(57.1 \%)$ were female and 2368 (42.9\%) were male, with female participation in significantly higher percentage compared to men $(\mathrm{p}<0.001)$. From the included OPG's, one or more impacted third molars were shown in 710 OPG-s: 414 $(58.3 \%)$ in women and $296(41.7 \%)$ in men; with gender ratio of 1:1.4 \{Table 1$\}$.

The age range was from 18 to 77 years (mean age $\pm S D=$ $29.3 \pm 12.8$ ). Men were older than women: mean age \pm SD $=32.1 \pm 14.6$ respectively $27.2 \pm 10.9, \mathrm{p}<0.001)$. Six working age groups were included in this research: 18-20, 21-30, 31-40, 41-50, 51-60 and greater than 60 \{Table 1\}. Pathologies associated with impacted teeth dominated in younger age groups, with their prevalence around $70 \%$ (preciously $27.5+42.3=69.8 \%)\{$ Table 1$\}$.

Table 2 presents a total number of 1297 impacted third molars that were found in both jaws.

Detectable radiographic lesions were seen in $383 \mathrm{im}$ pacted third molars. A significantly higher frequency of pathologies associated with those impactions were found significantly more in the maxilla compared to the mandible (26.2\%, $\mathrm{P}<0.001) .\{$ Table3\}. In maxilla 42.6\% $(36.9+5.7)$ of third impacted molar had one or two pathologies, whereas the prevalence of pathologies in third impacted molars was $21.5 \%(19.6+1.9)\{$ Table 4$\}$.in mandible

The prevalence of root resorption was the most frequent pathological condition with a prevalence of $23.7 \%$ in our studied teeth. It was followed by over $5 \mathrm{~mm}$ periodontal bone loss of the distal part of the second molar $5.5 \%$ and caries appearing in $2.5 \%$ cases. An increase in pericoronal space of the dental follicle over $4 \mathrm{~mm}$ around third impacted molar had the lowest prevalence of only $1.2 \%$ in an impacted third molar between the maxilla and mandible \{Table 3$\}$.

Table 5 shows there were no statistically significant differences in the prevalence of pathologies between male and female patients. The rates of pathological lesions observed in between left and right side had an equal prevalence of: $29.7 \%$ $(26.4+3.3)$ right and $29.4 \%(26.1+3.3)$ left side \{Table 6 and 7$\}$.

After evaluating the entire results, it could be noticed that in 1297 impacted teeth found in 710 OPG's, 70.5\% of those impacted third molars were not influenced by any of the four pathologies. On the other hand, $26.2 \%$ of the cases were influenced by at least one pathological lesion and 3.3\% of cases by two pathological lesions. impaktiranih trećih kutnjaka promatranih na 50 nasumično odabranih snimki korišstenjem statistike Kappa (36).

Dva tjedna nakon prve procjene, ocjenu je ponovio drugi ispitivač. Svi OPG-ovi ispitani su slijepim pristupom, bez mogućnosti procjene dobi i spola. Prosjek koeficijenata dobivenih za relevantne varijable ovoga istraživanja bio je značajan $(0,756)$.

\section{Rezultati}

U našoj retrospektivnoj studiji pregledali smo podatke 5515 odraslih pacijenata upućenih u UKCK - 3147 (57,1 \%) žena i 2368 (42,9 \%) muškaraca, s udjelom žena u znatno većem postotku u odnosu prema muškarcima ( $\mathrm{p}<0,001)$. Od uključenih OPG-ova, jedan ili više impaktiranih trećih kutnjaka prikazani su u njih $710-414(58,3 \%)$ kod žena i 296 (41,7 \%) kod muškaraca; s omjerom 1: 1,4 (tablica 1.).

Raspon dobi bio je od 18 do 77 godina (srednja dob \pm $\mathrm{SD}=29,3 \pm 12,8)$. Muškarci su bili stariji od žena - srednja dob iznosila je $\pm S D=32,1 \pm 14,6$, odnosno $27,2 \pm 10,9, p$ $<0,001)$. Šest dobnih skupina bilo je uključeno u ovo istraživanje: $18-20,21-30,31-40,41-50,51-60$ i više od 60 (tablica 1.). U mlađim dobnim skupinama prevladavale su patološke promjene povezane $s$ impaktiranim zubima, a njihova učestalost bila je oko $70 \%(27,5+42,3=69,8 \%)$ (tablica 1.).

Tablica 2. pokazuje 1297 impaktiranih trećih kutnjaka u objema čeljustima. Radiografski su ustanovljene patološke promjene povezane s 383 impaktirana treća kutnjaka. Utvrđeno je da je značajno veća učestalost patoloških promjena povezanih s tim impakcijama u maksili u usporedbi s mandibulom $(26,2 \%, \mathrm{P}<0,001)$ (tablica 3.). U maksili je 42,6 \% $(36,9+5,7)$ impaktiranih trećih kutnjaka imalo jednu ili dvije patološke promjene, a u mandibuli je učestalost patoloških promjena povezanih $s$ trećim kutnjacima bila $21,5 \%(19,6$ $+1,9)$ (tablica 4.).

Resorpcija korijena bila je najčešća patološka promjena s učestalošću od 23,7 \% na zubima koje smo ispitivali. Slijedio je gubitak parodontne kosti veći od $5 \mathrm{~mm}$ u distalnome dijelu drugog kutnjaka $-5,5 \%$, a karijes se pojavio u 2,5 \% slučajeva. Povećanje perikoronarnog prostora zubnog folikula veće od $4 \mathrm{~mm}$ oko impaktiranih trećih kutnjaka imalo je najnižu učestalost - samo 1,2 \% u objema čeljustima (tablica 3.).

Tablica 5. pokazuje da nema statistički značajnih razlika u učestalosti patoloških promjena između muškaraca i žena. Patološke promjene promatrane između lijeve i desne strane imale su istu učestalost $-29,7 \%(26,4+3,3)$ desno i $29,4 \%$ $(26,1+3,3)$ lijevo (tablice 6. i 7.).

Nakon procjene cjelokupnih rezultata moglo bi se uočiti da između 1297 impaktiranih zuba pronađenih na 710 OPG-ova, 70,5 \% impaktiranih trećih kutnjaka nisu imali udružene patološke promjene. S druge strane, 26,2 \% slučajeva imalo je jednu i 3,3 \% dvije patološke promjene. 
Table 1 Distribution of patients with impacted third molars according to age group

Tablica 1. Raspodjela pacijenata s impaktiranim trećim kutnjacima prema dobi

\begin{tabular}{c|c|c|c}
$\begin{array}{c}\text { Age groups } \\
\text { Dobne skupine }\end{array}$ & $\begin{array}{c}\text { Male } \bullet \text { Muškarci } \\
\text { N }(\%)\end{array}$ & $\begin{array}{c}\text { Female } \bullet \text { Žene } \\
\text { N }(\%)\end{array}$ & $\begin{array}{c}\text { Total } \bullet \text { Ukupno } \\
\text { N (\%) }\end{array}$ \\
\hline $18-20$ & $73(24.7)$ & $122(29.5)$ & $195(27.5)$ \\
\hline $21-30$ & $106(35.8)$ & $194(46.9)$ & $300(42.3)$ \\
\hline $31-40$ & $43(14.5)$ & $48(11.6)$ & $91(12.8)$ \\
\hline $41-50$ & $33(11.1)$ & $23(5.6)$ & $56(7.9)$ \\
\hline $51-60$ & $23(7.8)$ & $21(5.1)$ & $44(6.2)$ \\
\hline $61-77$ & $18(6.1)$ & $6(1.4)$ & $24(3.4)$ \\
\hline Total $\bullet$ Ukupno & $296(100)$ & $414(100)$ & $710(100)$ \\
\hline
\end{tabular}

Pearson Chi-Square value $=27.42, \mathrm{df}=5, \mathrm{P}<0.001,0$ cells $(0.0 \%)$ have expected count less than 5 . The minimum expected count is 10.01 .

Table 2 Prevalence of pathologies associated with impacted third molars according to age groups

Tablica 2. Učestalost patoloških promjena povezanih s impaktiranim trećim kutnjacima prema dobi

\begin{tabular}{|c|c|c|c|c|c|c|c|}
\hline $\begin{array}{c}\text { Pathologies } \\
\text { Patološke promjene }\end{array}$ & $\begin{array}{l}18-20 \\
\mathrm{~N}(\%)\end{array}$ & $\begin{array}{l}21-30 \\
N(\%)\end{array}$ & $\begin{array}{l}31-40 \\
N(\%)\end{array}$ & $\begin{array}{l}41-50 \\
N(\%)\end{array}$ & $\begin{array}{l}51-60 \\
N(\%)\end{array}$ & $\begin{array}{c}61-77 \\
N(\%)\end{array}$ & $\begin{array}{l}\text { Total • } \\
\text { Ukupno } \\
\text { N (\%) }\end{array}$ \\
\hline $\begin{array}{l}\text { Caries of impacted and /or adjacent teeth } \bullet \text { Karijes } \\
\text { impaktiranoga i/ili susjednoga zuba }\end{array}$ & $6(1.5)$ & $25(4.3)$ & $0(0.0)$ & $2(2.4)$ & $0(0.0)$ & $0(0.0)$ & $33(2.5)$ \\
\hline $\begin{array}{l}\text { Periodontal bone loss of adjacent tooth }>5 \mathrm{~mm} \bullet \\
\text { Gubitak parodontne kosti susjednoga zuba }>5 \mathrm{~mm}\end{array}$ & $43(10.9)$ & $24(4.2)$ & $2(1.4)$ & $1(1.2)$ & $1(1.6)$ & $0(0.0)$ & $71(5.5)$ \\
\hline $\begin{array}{l}\text { Root resorption of adjacent tooth }{ }^{a} \bullet \text { Resorpcija } \\
\text { korijena susjednog zuba }^{\text {a }}\end{array}$ & 85 (21.5) & $133(23.0)$ & $48(33.8)$ & $25(30.1)$ & $10(16.4)$ & $6(16.2)$ & 307 (23.7) \\
\hline $\begin{array}{l}\text { Increase in pericoronar gap } \bullet \text { Povećanje } \\
\text { perikoronarnoga prostora }\end{array}$ & $6(1.5)$ & $4(0.7)$ & $1(0.7)$ & $1(1.2)$ & $3(4.9)$ & $0(0.0)$ & $15(1.2)$ \\
\hline Total • Ukupno & $396(100)$ & $578(100)$ & $142(100)$ & $83(100)$ & $61(100)$ & $37(100)$ & $1297(100)$ \\
\hline
\end{tabular}

a Pearson Chi-Square value $=14,11, \mathrm{df}=5, \mathrm{P}=0,015.0$ cells $(0,0 \%)$ have expected count less than 5 . The minimum expected count is 8,76 .

Table 3 Prevalence of pathologies associated with impacted third molars according to jaw

Tablica 3. Učestalost patoloških promjena povezanih s impaktiranim trećim kutnjacima prema čeljustima

$$
\text { Pathologies • Patološke promjene }
$$

\begin{tabular}{|c|c|c|c|}
\hline $\begin{array}{c}\text { Maxilla } \bullet \text { Maksila } \\
\mathrm{N}(\%)\end{array}$ & $\begin{array}{c}\text { Mandibula } \\
\mathrm{N}(\%)\end{array}$ & $\begin{array}{c}\text { Total } \bullet \text { Ukupno } \\
\mathrm{N}(\%)\end{array}$ \\
\hline $32(6.5)$ & $1(0.1)$ & $33(2.5)^{\mathrm{a}}$ \\
\hline $32(6.5)$ & $39(4.9)$ & $71(5.5)^{\mathrm{b}}$ \\
\hline $159(32.3)$ & $148(18.4)$ & $307(23.7)^{\mathrm{c}}$ \\
\hline & $15(3.0)$ & $0(0.0)$ & $15(1.2)^{\mathrm{d}}$ \\
\hline
\end{tabular}

Caries of impacted and /or adjacent teeth •

Karijes impaktiranoga i/ili susjednoga zuba

Periodontal bone loss of adjacent tooth $>5 \mathrm{~mm} \bullet$

Gubitak parodontne kosti susjednoga zuba $>5 \mathrm{~mm}$

Root resorption of adjacent tooth $\bullet$

Resorpcija korijena susjednoga zuba

Increase in pericoronar gap $\bullet$

Povećanje perikoronarnoga prostora

Total $\bullet$ Ukupno

a Fisher's exact test, chi-square value $=47,42, \mathrm{df}=1, \mathrm{P}<0,001.0$ cells $(0,0 \%)$ have expected count less than 5 . The minimum expected count is 12,54 . b Fisher's exact test is not significant.

c Fisher's exact test, chi-square value $=31,66, \mathrm{df}=1, \mathrm{P}<0,001.0$ cells $(0,0, \%)$ have expected count less than 5 . The minimum expected count is 116,69 . $\mathrm{d}$ Fisher's exact test, chi-square value $=22,16, \mathrm{df}=1, \mathrm{P}<0,001.0$ cells $(0,0, \%)$ have expected count less than 5 . The minimum expected count is 5,70 .

Table 4 Number of pathologies associated with impacted teeth according to jaw

Tablica 4. Broj patoloških promjena povezanih s impaktiranim zubima prema čeljustima

\begin{tabular}{|c|c|c|c|}
\hline $\begin{array}{c}\text { Pathologies } \\
\text { Patološke promjene }\end{array}$ & $\begin{array}{c}\text { Maxilla } \bullet \text { Maksila } \\
\text { N (\%) }\end{array}$ & $\begin{array}{l}\text { Mandibula } \\
\text { N (\%) }\end{array}$ & $\begin{array}{c}\text { Total } \bullet \text { Ukupno } \\
\mathrm{N}(\%)\end{array}$ \\
\hline 0 & $283(57.4)$ & $631(78.5)$ & $914(70.5)$ \\
\hline 1 & $182(36.9)$ & $158(19.6)$ & $340(26.2)$ \\
\hline 2 & $28(5.7)$ & $15(1.9)$ & $43(3.3)$ \\
\hline Total • Ukupno & $493(100)$ & $804(100)$ & $1297(100)$ \\
\hline
\end{tabular}

Pearson Chi-Square value $=67,43, \mathrm{df}=2, \mathrm{P}<0,001.0$ cells $(0,0 \%)$ have expected count less than 5 . The minimum expected count is 16,34 . 
Table 5 Prevalence of pathologies associated with impacted third molars according to sex

Tablica 5. Učestalost patoloških promjena povezanih s impaktiranim trećim kutnjacima prema spolu

\begin{tabular}{|c|c|c|c|}
\hline Pathologies • Patološke promjene & $\begin{array}{l}\text { Male } \bullet \text { Muškarci } \\
\text { N (\%) }\end{array}$ & $\begin{array}{l}\text { Female } \bullet \text { Žene } \\
\mathrm{N}(\%)\end{array}$ & $\begin{array}{l}\text { Total } \bullet \text { Ukupno } \\
\text { N (\%) }\end{array}$ \\
\hline $\begin{array}{l}\text { Caries of impacted and /or adjacent teeth } \\
\text { Karijes impaktiranoga i/ili susjednoga zuba }\end{array}$ & $8(1.5)$ & $25(3.2)$ & $33(2.5)^{a}$ \\
\hline $\begin{array}{l}\text { Periodontal bone loss of adjacent tooth }>5 \mathrm{~mm} \\
\text { Gubitak parodontne kosti susjednoga zuba }>5 \mathrm{~mm}\end{array}$ & $25(4.8)$ & $46(5.9)$ & $71(5.5)^{b}$ \\
\hline $\begin{array}{l}\text { Root resorption of adjacent tooth } \\
\text { Resorpcija korijena susjednoga zuba }\end{array}$ & $121(23.3)$ & $186(23.9)$ & $307(23.7)^{\mathrm{c}}$ \\
\hline $\begin{array}{l}\text { Increase in pericoronar gap } \\
\text { Povećanje perikoronarnoga prostora }\end{array}$ & $6(1.2)$ & $9(1.2)$ & $15(1.2)^{d}$ \\
\hline Total • Ukupno & $520(100)$ & $777(100)$ & $1297(100)$ \\
\hline
\end{tabular}

$\mathrm{a}, \mathrm{b}, \mathrm{c}, \mathrm{d}$ Fisher's exact test is not significant.

Table 6 Number of pathologies associated with impacted third molar according to side in OPG's

Tablica 6. Broj patoloških promjena povezanih s impaktiranim trećim kutnjacima prema stranama čeljusti

\begin{tabular}{|c|c|c|c|}
\hline Pathologies $\bullet$ Patološke promjene & $\begin{array}{c}\text { Right } \bullet \text { Desno } \\
\mathrm{N}(\%)\end{array}$ & $\begin{array}{c}\text { Left } \bullet \text { Lijevo } \\
\mathrm{N}(\%)\end{array}$ & $\begin{array}{c}\text { Total • Ukupno } \\
\text { N (\%) }\end{array}$ \\
\hline 0 & $421(70.3)$ & $493(70.6)$ & $914(70.5)$ \\
\hline 1 & $158(26.4)$ & $182(26.1)$ & $340(26.2)$ \\
\hline 2 & $20(3.3)$ & $23(3.3)$ & $43(3.3)$ \\
\hline Total • Ukupno & $599(100)$ & $698(100)$ & $1297(100)$ \\
\hline
\end{tabular}

Pearson Chi-Square value $=0,02, \mathrm{df}=2, \mathrm{P}=0,991.0$ cells $(0,0 \%)$ have expected count less than 5 . The minimum expected count is 19,86 .

\begin{tabular}{|c|c|c|c|}
\hline Pathologies • Patološke promjene & $\begin{array}{c}\text { Right side } \bullet \text { Desna strana } \\
\mathrm{N}(\%)\end{array}$ & $\begin{array}{c}\text { Left side } \bullet \text { Lijeva strana } \\
\mathrm{N}(\%)\end{array}$ & $\begin{array}{c}\text { Total } \bullet \text { Ukupno } \\
\text { N }(\%)\end{array}$ \\
\hline $\begin{array}{l}\text { Caries of impacted and /or adjacent teeth } \\
\text { Karijes impaktiranoga i/ili susjednoga zuba }\end{array}$ & $14(2.3)$ & $19(2.7)$ & $33(2.5)^{\mathrm{a}}$ \\
\hline $\begin{array}{l}\text { Periodontal bone loss of adjacent tooth }>5 \mathrm{~mm} \\
\text { Gubitak parodontne kosti susjednoga zuba }>5 \mathrm{~mm}\end{array}$ & $31(5.2)$ & $40(5.7)$ & $71(5.5)^{b}$ \\
\hline $\begin{array}{l}\text { Root resorption of adjacent tooth } \\
\text { Resorpcija korijena susjednoga zuba }\end{array}$ & $150(25.0)$ & $157(22.5)$ & $307(23.7)^{c}$ \\
\hline $\begin{array}{l}\text { Increase in pericoronar gap } \\
\text { Povećanje perikoronarnoga prostora }\end{array}$ & $3(0.5)$ & $12(1.7)$ & $15(1.2)^{d}$ \\
\hline Total $\bullet$ Ukupno & $599(100)$ & $698(100)$ & $1297(100)$ \\
\hline
\end{tabular}

$\mathrm{a}, \mathrm{b}, \mathrm{c}, \mathrm{d}$ Fisher's exact test is not significant.

\section{Discussion}

Currently dental practitioners and oral surgeons face challenges to determine a constant guiding principle regarding the extraction of asymptomatic third molar impaction $(11,37,38)$.

However, according to a compromise conference held for removal of third molar impaction there is almost no controversy concerning the removal of impacted third molars when pathologies are associated with them $(14,39)$. They defined criteria for impacted third molar removal, indicating that surgery should be carried out as soon as possible once the diagnose is made for a non-restorable caries of adjacent or im-

\section{Rasprava}

Trenutačno se stomatolozi i oralni kirurzi suočavaju s izazovima u određivanju smjernica o ekstrakciji asimptomatskih impaktiranih trećih kutnjaka $(11,37,38)$.

No, prema onomu što se čulo na konferenciji o toj temi, gotovo nema nikakvih kontroverzija u vezi s uklanjanjem trećeg kutnjaka kada su s njima povezane patološke promjene $(14,39)$. Nazočni su definirali kriterije za uklanjanje impaktiranih trećih kutnjaka, ističući da se terapija mora provesti što je prije moguće ako se dijagnosticira neobnovljivi karijes susjednih ili impaktiranih zuba, resorpcija susjednih zuba, destrukcija kosti, bolesti folikula i infekcije $(14,39)$. Ipak, mora 
pacted teeth, resorption of adjacent teeth, bone destruction, follicle disease and infections $(14,39)$. Nevertheless, it is also significantly important to highlight the fact that the Scottish Intercollegiate Guideline Network has rejected a prophylactic extraction of asymptomatic impacted third molars (40). This extraction rejection may be a result of deficient evidence supporting prophylactic extraction of these teeth (11).

Bearing in mind the significant importance of having data on the incidence of pathologies associated with the impacted third molar, the main focus of our study was its epidemiology and prevalence in a Kosovar population.

To determine the prevalence of pathologies associated with an impacted third molar is challenging due to the difficulties that emerge due to the fact that a random sample from the general population is required. Obtaining such samples is admittedly complex because of the arguable ethical considerations and associated costs $(1,25)$. In order to avoid such a bias, our target was to evaluate the OPGs of the patients that have already been taken at the UDCCK.

The prevalence of pathologies in our study is shown in Table 3. From the literature, it has been reported that the impactions of the third molars have been causing root resorption of adjacent second molars $(1,25)$. Our evaluation of the tooth resorption between maxilla and mandible showed the prevalence of $23.7 \%$. Our finding shows a much higher prevalence of root resorption compared to the findings of similar studies of a Honk Kong Chinese population by Chu et al (25) who reported a total figure of only $13(0.4 \%)$ cases of resorption amongst over 3000 impacted third molars. Also, it is different from the findings by van Der Linden et all who reported a prevalence of only $0.9 \%$ in 2872 impacted third molars (1). On the contrary, the finding by Ahlqwist et al (42), in a study of 121 impacted third molars, reported only one case of second molar resorption, whereas Sewerin and von Wowern reported about a zero second molar impaction (36).

The variation of tooth resorption prevalence can be explained by diverse definitions of root resorption in different studies. In this study, root resorption was defined as a clear loss of the tooth substance, while a group of researches (27) defined root resorption as an irregularity and discontinuity of the root surface. Furthermore, Stanley et al have emphasized that it is complicated to determine radiologically if coronal radiolucency of second molar adjacent to third molar is due to caries or root resorption (29).

The periodontal bone loss of the distal part of the second molar more than $5 \mathrm{~mm}$ below the cemento-enamel junction in our study group was (5.5\%) and this was second largest pathology associated with impacted third molars. On the other hand, it was the highest score of pathology reported in data by $\mathrm{Chu}$ et al. They reported about the prevalence of approximately $9 \%$ of periodontal bone loss of more than $5 \mathrm{~mm}$ in second mandibular molar adjacent to impacted third molar in 3778 impacted third molars (25). Wynand van der Linden et al (1), obtained a similar finding to our study of periodontal bone loss of $4.9 \%$, pathology which was mostly located in mandible. In our study, the maxilla had significantly higher prevalence of periodontal bone loss with $32.2 \%$, compared to se istaknuti da je Scottish Intercollegiate Guideline Network odbio profilaktičnu ekstrakciju asimptomatskih impaktiranih trećih kutnjaka (40). To može biti rezultat nedostatka dokaza koji podupiru profilaktičnu ekstrakciju tih zuba (11).

Imajući na umu važnost podataka o učestalosti patoloških promjena povezanih s trećim kutnjacima, naše je istraživanje bilo usmjereno na epidemiologiju i učestalost u kosovskom stanovništvu.

Utvrđivanje učestalosti patoloških promjena povezanih s impaktiranim trećim kutnjakom dosta je izazovno zbog poteškoća koje se pojavljuju, jer se zahtijeva nasumični uzorak opće populacije. Dobivanje takvih uzoraka je, doduše, složeno zbog opravdanih etičkih razmatranja i povezanih troškova $(1,25)$. Kako bismo izbjegli takvu pristranost, naše istraživanje provedeno je na pacijentima koji su već pri uobičajenom pregledu učinili OPG u UDCCK-u.

Učestalost patoloških promjena u našem istraživanju prikazana je u tablici 3. U literaturi je objavljeno da je impakcija trećih kutnjaka uzrokovala resorpciju korijena susjednoga drugog kutnjaka $(1,25)$. Naša procjena resorpcije zuba obiju čeljusti pokazala je učestalost od $23,7 \%$. Naši rezultati pokazuju mnogo veću učestalost resorpcije korijena u usporedbi s nalazima sličnih istraživanja kineske populacije u Hong Kongu, koju su objavili Chu i suradnici (25) te pronašli učestalost u samo $13(0,4 \%)$ slučajeva između više od 3000 impaktiranih trećih kutnjaka. Također se razlikuje od nalaza van der Lindena i suradnika koji su izvijestili o učestalosti od samo 0,9 među 2872 impaktirana treća kutnjaka (1). Suprotno tomu, nalaz Ahlqwista i suradnika. (42) u studiji o 121-nom impaktiranom trećem kutnjaku pokazuje samo jedan slučaj resorpcije drugoga kutnjaka, a Sewerin i von Wowern izvijestili su da nisu ustanovili ni jednu resorpciju drugog kutnjaka (36).

Različita učestalost može se objasniti različitim definicijama resorpcije korijena u različitim studijama. U našoj je studiji resorpcija korijena definirana kao jasan gubitak zubne tvari, a u skupini istraživanja (27) resorpcija korijena definirana je kao nepravilnost i diskontinuitet površine korijena. Nadalje, Stanley i suradnici istaknuli su da je navedeno vrlo složeno odrediti radiološki ako je koronarno prosvjetljenje drugoga kutnjaka uz treći kutnjak posljedica karijesa ili resorpcije korijena (29).

Gubitak parodontne kosti distalnoga dijela drugog kutnjaka veći od $5 \mathrm{~mm}$ ispod caklinsko-cementnoga spojišta u našem istraživanju bio je 5,5\% i to je druga najveća patološka promjena povezana s impaktiranim trećim kutnjacima. $S$ druge strane, to je bila najveća patološka promjena u istraživanju Chua i suradnika koji su na 3778 impaktiranih trećih kutnjaka našli učestalost od oko $9 \%$ gubitka parodontne kosti veću od $5 \mathrm{~mm}$ drugih donjih kutnjaka u blizini trećega kutnjaka (25). Wynand van der Linden i suradnici (1) uočili su nalaz sličan našem istraživanju gubitka parodontne kosti od 4,9\%, a patološka promjena uglavnom se nalazila u mandibuli. $U$ našemu istraživanju ustanovljena je u maksili značajno veća učestalost gubitka parodontne kosti - 32,2 \%, u odnosu prema mandibuli od samo 18,4\%. Mercier i Precious zaključili su da je usporedba gubitka parodontne kosti vrlo zahtjevna zbog uporabe različitih definicija o istom stanju (14). 
the mandible with only $18.4 \%$. In their study, Mercier and Precious stated that it is challenging to compare periodontal bone loss due to the use of dissimilar definitions about the same condition (14).

In our study, we have found that in 1238 impacted teeth, caries occurred only in $2.5 \%$ of the teeth studied. Caries not being dominating pathology in our study, is dissimilar to retrospective finding in a study of 1001 OPG's of patients that visited dental school (1) The percentage of caries in impacted third molars or adjacent molars was $7.1 \%$ and $42.7 \%$, respectively. In general, their finding was consistent with other studies $(23,41)$. Nevertheless, caries figures found in our study might be underrated because the diagnosis of caries was based only on OPG's.

In previous radiographically based studies researching increased coronal radiolucency surrounding impacted third molar over $4 \mathrm{~mm}$ reported the frequency of no more than $1 \%(40,42)$. In our study, we observed coronal radiolucency of $(1.2 \%)$ with its higher percentage located in mandible. However, in studies when a space of $>3 \mathrm{~mm}$ for widened coronal radiolucency was used, the prevalence of the pathology for both jaws was up to $4.6 \%$ (1). Assessing the coronal radiolucency changes, Stephens emphasized the importance of attentiveness in order to avoid confusing a follicular space enlargement with a developing dentigerous cyst (43). He believed that inaccuracy appears when follicular space $>2.5 \mathrm{~mm}$ in radiographic examinations is classified as cyst.

On the other hand, follicular tissues of radiologically normal teeth when examined histologically showed that in 34\% to $46.5 \%$ of cases $(31,32,44)$ had histological findings pinpointing of dentigerous cyst formation. Therefore, radiographic appearance may not be an exceptionally dependable indicator of the absence of disease within the dental follicle.

\section{Study Limitations}

Study samples were taken only from the University Clinical Center of Kosovo. This clinical center is the main health, education, and research institution for dentistry in Kosovo. The sample size represents $0.44 \%$ of the population. However, the sample of the patients with impacted third molars featured a slight dominance of females over males, which may have been a consequence of female patients having higher awareness regarding their oral health.

\section{Conclusion}

Evaluating the prevalence of pathologies associated with impacted third molar in a certain population contributes to making a comparison pattern in different regions and populations worldwide.

Our data in Kosovar population show that the prevalence of pathologies is $29.5 \%$ with a distinct predilection of pathologies in impacted third maxillary molars. The most common pathology appeared to be root resorption of adjacent tooth, followed by periodontal bone loss, caries and increased pericoronal radiolucency.

An early detection and data about the prevalence of pathologies associated with impacted third molar is essential in order to accomplish an effective treatment. Despite the fact
U našem istraživanju utvrdili smo da se na 1238 impaktiranih zuba karijes pojavio samo na 2,5 \% ispitivanih zuba. Karijes nije dominantna patološka promjena u našem istraživanju i različita je od retrospektivnog nalaza u studiji o 1001 OPG-u (1). U njemu je postotak karijesa impaktiranih trećih kutnjaka ili susjednih drugih kutnjaka bio $7,1 \%$, odnosno $42,7 \%$. Taj nalaz općenito je u skladu s rezultatima drugih istraživanja $(23,41)$. Ipak, broj karijesa u našem istraživanju mogao bi biti podcijenjen u odnosu prema stvarnoj stopi karijesa, jer se dijagnoza temelji samo na OPG-ovima.

$\mathrm{U}$ dosadašnjim radiografski temeljenim istraživanjima, za povećanu perikoronarnu transparenciju impaktiranoga trećega kutnjaka veću od $4 \mathrm{~mm}$, učestalost nije bila veća od $1 \%$ $(40,42)$. U našem istraživanju zabilježena je perikoronarna transparencija od $1,2 \%$, s većim postotkom u donjoj čljusti. No u istraživanjima u kojima je bila uključena perikoronarna transparencija veća od $3 \mathrm{~mm}$, učestalost te patološke promjene iznosila je 4,6 \% ukupno u objema čeljustima (1). Procjenjujući promjene perikoronarnih transparencija, Stephens je istaknuo koliko je važan oprez kako bi se izbjegla zabuna između povećanog perikoronarnog prostora i odontogene razvojne ciste (43). Smatrao je da se netočnost pojavljuje kada se folikularni prostor $>2,5 \mathrm{~mm}$ tijekom radiografskih pregleda klasificira kao cista.

$S$ druge strane, kada se folikularno tkivo radiološki normalnih zuba ispitalo histološki, pokazalo se da su u $34 \%$ do $46,5 \%$ slučajeva $(31,32,44)$ histološki nalazi upozoravali na nastanak cistične formacije. Zato radiografski nalaz ne mora biti iznimno pouzdan pokazatelj odsutnosti bolesti unutar zubnoga folikula.

\section{Ograničenja studije}

Uzorci za istraživanje dobiveni su samo od Sveučilišnoga kliničkog centra Kosova. Taj klinički centar glavna je zdravstvena, obrazovna i istraživačka ustanova za stomatologiju na Kosovu. Veličina uzorka iznosi $0,44 \%$ stanovništva. No uzorak pacijenata $s$ impaktiranim trećim kutnjacima pokazuje malu dominacije žena u odnosu prema muškarcima, što je možda posljedica veće svijesti žena o oralnome zdravlju.

\section{Zaključak}

Procjena učestalosti patoloških promjena povezanih s impaktiranim trećim kutnjacima u određenoj populaciji pridonosi usporedbi uzorka u različitim regijama i populacijama diljem svijeta.

Naši podatci o kosovskoj populaciji pokazuju da je učestalost patoloških promjena 29,5\%, češće na impaktiranim trećim gornjim kutnjacima. Najčešća patološka promjena jest resorpcija korijena susjednoga zuba, zatim gubitak periferne kosti, karijes i povećana perikoronarna transparencija.

$\mathrm{Da}$ bi se postiglo učinkovito liječenje, prijeko je potrebno rano otkrivanje i podatci o učestalosti patoloških promjena povezanih $s$ impaktiranim trećim kutnjacima. lako je u našem istraživanju učestalost povezanih patoloških promjena 
that the prevalence of associated pathologies is considerably low in our study, it is of utmost importance to carry out regular examinations in order to keep the asymptomatic impacted third molars in good oral health.

Further studies are highly recommended and needed in Kosovo and the region.

\section{Conflict of interest}

\author{
None declared
}

razmjerno niska, iznimno je važno provoditi redovite preglede kako bi se asimptomatski impaktirani treći kutnjaci održali u dobrom stanju, a time i dobro oralno zdravlje. Preporučujemo daljnja slična istraživanja na Kosovu i u regiji.
Sažetak

Cilj: Budući da u literaturi nema dostupnih podataka, ovim se istraživanjem procjenjivala učestalost radioloških patoloških promjena povezanih s impaktiranim trećim kutnjacima među kosovskim stanovništvom. Materijali i postupci: Ovo je retrospektivna studija 5515 ortopantomograma (OPG ova) pacijenata pregledanih u Sveučilišnom kliničkom centru Kosova (UDCCK-u). Pregledano je 2368 snimaka muškaraca i 3147 žena u dobi od 18 do 77 godina. Analizom snimki ustanovili smo broj i vrstu patoloških promjena povezanih s impaktiranim trećim kutnjacima. Zabilježene su sljedeće radiografski vidljive patološke promjene: karijes impaktiranih i/ili susjednih zuba, resorpcija korijena susjednih zuba, gubitak parodontne kosti susjednih zuba, gubitak parodontne kosti susjednih zuba veći od $5 \mathrm{~mm}$ ispod caklinsko-cementnog spojišta i proširenje perikoronarnog prostora više od 4 $\mathrm{mm}$. Rezultati: Učestalost patoloških promjena povezanih s impaktiranima trećim kutnjacima među kosovskim stanovništvom iznosila je $29,5 \%$. Najčešća je bila resorpcija korijena susjednog zuba $307(23,7 \%$ ). Slijedio je gubitak parodontne kosti susjednoga zuba veći od $5 \mathrm{~mm}-1$ (5,5\%) i karijes - 33 (2,5\%). Najmanja je bila učestalost proširenoga perikoronarnog prostora veća od $4 \mathrm{~mm}-15$ $(1,2 \%)$. Zaključak: Najčešća patološka promjena povezana s impaktiranim trećim kutnjacima bila je resorpcija korijena susjednoga zuba, s najvećom učestalošću u maksili - 159 (32,3 \%). Značajno manja učestalost zabilježena je za gubitak parodontne kosti, karijes i proširenje perikoronarnog prostora. Rezultati našega istraživanja mogli bi utjecati na razvoj preventivnih strategija patoloških promjena koje su posljedica impaktiranih trećih kutnjaka.
Zaprimljen: 9. prosinca 2018. Prihvaćen: 12. ožujka 2019.

Adresa za dopisivanje

Zana Sejfija

Student doktorskog studija

Sveučilište u Zagrebu

Stomatološki fakultet

Sveučilište u Prištini

Rr. Bulevardi i Dëshmorëve, p.n.

10000 Pristina, Kosovo

tel: +37744169076

zana.sejfija@uni-pr.edu

Ključne riječi

uklještenje zuba; panoramska radiografija; resorpcija korijena zuba; zubni karijes; gubitak alveolarne kosti; učestalost; treći kutnjak

\section{References}

1. van der Linden W, Cleaton-Jones P, Lownie M. Diseases and lesions associated with third molars: Review of 1001 cases. Oral Surg Oral Med Oral Pathol Oral Radiol Endod. 1995;79(2):142-5.

2. Akarslan ZZ, Kocabay C. Assessment of the associated symptoms, pathologies, positions and angulations of bilateral occurring mandibular third molars: Is there any similarity? Oral Surg Oral Med Oral Pathol Oral Radiol Endod. 2009;108(3):e26-e32.

3. Bishara SE, Andreasen G. Third molars: a review. Am J Orthod. 1983;83(2):131-7.

4. Grover PS, Lorton L. The incidence of unerupted permanent teeth and related clinical cases. Oral Surg Oral Med Oral Pathol. 1985;59(4):420-5.

5. Nazir A, Akhtar MU, Ali S. Assessment of different patterns of impacted mandibular third molars and their associated pathologies. J Adv Med Dent Scie. 2014;2(2):14-22.

6. Jokić D, Macan D, Perić B, Tadić M, Biočić J, Đanić P, et al. Ambulatory oral surgery: 1-year experience with 11680 patients from Zagreb district, Croatia. Croat Med J. 2013 Feb;54(1):49-54.

7. Gisakis IG, Palamidakis FD, Farmakis ETR, Kamberos G, Kamberos S. Prevalence of impacted teeth in a Greek population. J Investig Clin Dent. 2011;2(2):102-9.

8. Pursafar F, Salemi F, Dalband M, Khamverdi Z. Prevalence of impacted teeth and their radiographic signs in panoramic radiographs of patients referred to Hamadan dental school in 2009. DJH. 2011;3(1):21-7.

9. Pedro F, Bandéca MC, Volpato L, Marques A, Borba AM, Musis C, et al. Prevalence of impacted teeth in a Brazilian subpopulation. J Contemp Dent Pract. 2014;15(2):209-13.

10. Tsvetanov T, Pechalova P. Tooth Impaction. Lambert Academic Publishing; 2016.

11. Al-Khateeb TH, Bataineh AB. Pathology associated with impacted mandibular third molars in a group of Jordanians. J Oral Maxillofac Surg. 2006;64(11):1598-602.

12. Polat HB, Özan F, Kara Is, Özdemir H, Ay S. Prevalence of commonly found pathoses associated with mandibular impacted third molars based on panoramic radiographs in Turkish population. Oral Surg Oral Med Oral Pathol Oral Radiol Endod. 2008;105(6):e41e7.
13. Song F, O'meara S, Wilson P, Golder S, Kleijnen J. The effectiveness and cost-effectiveness of prophylactic removal of wisdom teeth. Health Technol Assess. 2000;4(15):1-55.

14. Mercier P, Precious D. Risks and benefits of removal of impacted third molars: a critical review of the literature. Int J Oral Maxillofac Surg. 1992;21(1):17-27.

15. Guralnick W. NIH consensus development conference for removal of third molars. J Oral Surg. 1980;38:235-6.

16. NICE. Guidance on the extraction of wisdom teeth. London: National Institute for Health and Care Excellence; 2000. [cited Feb 11]. Available from: https://www.nice.org.uk/guidance/ ta1/resources/guidance-on-the-extraction-of-wisdom-teethpdf-63732983749

17. Scottish Intercollegiate Guideline Network. Management of unerupted and impacted third molar teeth. (SIGN GUIDELINE 43), Edinburgh: Royal College of Physicians; 2000. [cited Feb 11]. Available from: http://www.maxilofacialchile.cl/es/socios/descargas/13.pdf

18. Brickley M, Kay E, Shepherd JP, Armstrong RA. Decision analysis for lower-third-molar surgery. Med Decis Making. 1995;15(2):14351.

19. Tulloch JC, Antczak AA, Wilkes JW. The application of decision analysis to evaluate the need for extraction of asymptomatic third molars. J Oral Maxillofac Surg. 1987;45(10):855-63.

20. Tulloch J, Antczak-Bouckoms A. Decision analysis in the evaluation of clinical strategies for the management of mandibular third molars. J Dent Educ. 1987;51(11):652-60.

21. Baranović M, Macan D. Alveotomy of the wisdom tooth: Indications and cotraindications in theory and practice. Acta stomatol Croat. 2004;38(4):297-8.

22. Sewerinl, von Wowern N. A radiographic four-year follow-up study of asymptomatic mandibular third molars in young adults. Int Dent J. 1990;40(1):24-30.

23. Girod S, Gerlach K-L, Krueger G. Cysts associated with long standing impacted third molars. Int J Oral Maxillofac Surg. 1993;22(2):110-2.

24. Litonjua L. Pathologic changes associated with the angulation of impacted mandibular third molars. J Philippine Dent Assoc. 1997;49(1):14-9. 
25. Chu F, Li T, Lui V, Newsome P, Chow R, Cheung L. Prevalence of impacted teeth and associated pathologies-a radiographic study of the Hong Kong Chinese population. Hong Kong Med J. 2003;9(3):158-63.

26. Yamaoka M, Furusawa K, Ikeda M, Hasegawa T. Root resorption of mandibular second molar teeth associated with the presence of the third molars. Aust Dent J. 1999;44(2):112-6.

27. Nitzan D, Keren T, Marmary Y. Does an impacted tooth cause root resorption of the adjacent one? Oral Surg Oral Med Oral Pathol. 1981;51(3):221-4.

28. Güven O, Keskin A, Akal ÜK. The incidence of cysts and tumors around impacted third molars. Int J Oral Maxillofac Surg. 2000 29(2):131-5.

29. Stanley HR, Alattar M, Collett WK, Stringfellow Jr HR, Spiegel EH. Pathological sequelae of "neglected" impacted third molars. I Oral Pathol Med. 1988 17(3):113-7.

30. Eliasson S HA, Nordenram A. Pathological changes related to long-term impaction of third molars: A radiographic study. Int J Oral Maxillofac Surg. 1989 18(4):210-2.

31. Adelsperger J, Campbell JH, Coates DB, Summerlin DJ, Tomich CE. Early soft tissue pathosis associated with impacted third molars without pericoronal radiolucency. Oral Surg Oral Med Oral Patho Oral Radiol Endod. 2000;89(4):402-6.

32. Manganaro AM. The likelihood of finding occult histopathology in routine third molar extractions. Gen Dent. 1998;46(2):200-2.

33. Korotkikh NG, Bobrovskikh MP, Serdiukov luP. Clinical, topographic, and morphological characteristics of pathological processes in the retromolar zone. Stomatologiia (Mosk). 2001;80(2):25-8.

34. Curran AE, Damm DD, Drummond JF. Pathologically significant pericoronal lesions in adults: histopathologic evaluation. J Oral Maxillofac Surg. 2002;60(6):613-7.
35. Kahl B, Gerlach K, Hilgers RD. A long-term, follow-up, radiographic evaluation of asymptomatic impacted third molars in orthodontically treated patients. Int J Oral Maxillofac Surg. 1994;23(5):27985.

36. Landis JR, Koch GG. The measurement of observer agreement for categorical data. Biometrics. 1977;33(1):159-74.

37. Knutsson K, Brehmer B, Lysell L, Rohlin M. Asymptomatic mandibular third molars: oral surgeons' judgment of the need for extraction. J Oral Maxillofac Surg. 1992;50(4):329-33.

38. Hyomoto M, Kawakami M, Inoue M, Kirita T. Clinical conditions for eruption of maxillary canines and mandibular premolars associated with dentigerous cysts. Am J Orthod Dentofacial Orthop. 2003;124(5):515-20.

39. Peterson LJ. Principles of management of impacted teeth. In: Hupp RJ. Contemporary oral and maxillofacial surgery. 3rd ed. St Louis: Mosby; 1998. p. 215-48.

40. Richards D. Management of unerupted and impacted third molar teeth. A National Clinical Guideline. Evidence-Based Dentistry. 2000;2(2):44

41. Shugars DA, Jacks MT, White Jr RP, Phillips C, Haug RH, Blakey $\mathrm{GH}$. Occlusal caries experience in patients with asymptomatic third molars. J Oral Maxillofac Surg. 2004;62(8):973-9.

42. Ahlqwits M, Gröndahl HG. Prevalance of impacted teeth and associated pathology in middle aged and older Swedish population. Community Dent Oral Epidemiol 1991;19(2):116-9.

43. Stephens RG, Kogon S, Reid J. The unerupted or impacted third molar--a critical appraisal of its pathologic potential. J Can Dent Assoc. 1989;55(3):201-7.

44. Glosser J, Campbell J. Pathologic change in soft tissues associated with radiographically 'normal'third molar impactions. Br J Oral Maxillofac Surg. 1999;37(4):259-60. 